\title{
Author Correction: Short-Course, High-Dose Rifampicin Achieves Wolbachia Depletion Predictive of Curative Outcomes in Preclinical Models of Lymphatic Filariasis and Onchocerciasis
}

Ghaith Aljayyoussi ${ }^{1}{ }^{1}$, Hayley E. Tyrer ${ }^{1}$, Louise Ford ${ }^{1}{ }^{1}$, Hanna Sjoberg ${ }^{1}$, Nicolas Pionnier ${ }^{1}$, David Waterhouse $^{1}$, Jill Davies ${ }^{1}$, Joanne Gamble ${ }^{1}$, Haelly Metuge ${ }^{2,3}$, Darren A. N. Cook ${ }^{1}$, Andrew Steven ${ }^{1}$, Raman Sharma ${ }^{1}$, Ana F. Guimaraes ${ }^{1}$, Rachel H. Clare ${ }^{1}$, Andrew Cassidy ${ }^{1}$, Kelly L. Johnston ${ }^{1}$, Laura Myhill1 ${ }^{1}$, Laura Hayward ${ }^{1}$, Samuel Wanji ${ }^{2,3}$, Joseph D. Turner ${ }^{1}$, Mark J. Taylor ${ }^{1}$ \& Stephen A. Ward ${ }^{1}$

Correction to: Scientific Reports https://doi.org/10.1038/s41598-017-00322-5, published online 16 March 2017

The original version of this Article contained a typographical error in the spelling of the author Haelly Metuge, which was incorrectly given as Haelly Metugene.

This has now been corrected in the PDF and HTML versions of the Article.

(i) Open Access This article is licensed under a Creative Commons Attribution 4.0 International c. License, which permits use, sharing, adaptation, distribution and reproduction in any medium or format, as long as you give appropriate credit to the original author(s) and the source, provide a link to the Creative Commons license, and indicate if changes were made. The images or other third party material in this article are included in the article's Creative Commons license, unless indicated otherwise in a credit line to the material. If material is not included in the article's Creative Commons license and your intended use is not permitted by statutory regulation or exceeds the permitted use, you will need to obtain permission directly from the copyright holder. To view a copy of this license, visit http://creativecommons.org/licenses/by/4.0/.

(C) The Author(s) 2018

\footnotetext{
${ }^{1}$ Department of Parasitology, Liverpool School of Tropical Medicine, Pembroke Place, Liverpool, L3 50 A, UK. ${ }^{2}$ Research Foundation in Tropical Medicine and the Environment, Buea, Cameroon. ${ }^{3}$ Department of Microbiology and Parasitology, University of Buea, Buea, Cameroon. Correspondence and requests for materials should be addressed to M.J.T. (email: Mark.Taylor@Istmed.ac.uk)
} 